\title{
Expression and prognostic analyses of the insulin-like growth factor 2 mRNA binding protein family in human pancreatic cancer
}

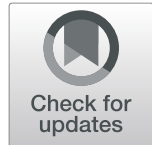

\author{
Xiao-Han Cui ${ }^{1,2}$, Shu-Yi Hu ${ }^{3}$, Chun-Fu Zhu ${ }^{1 *}$ and Xi-Hu Qin ${ }^{1 *}$ (D)
}

\begin{abstract}
Background: Despite advances in early diagnosis and treatment, cancer remains the leading cause of mortality worldwide. The insulin-like growth factor 2 mRNA binding protein (IGF2BP) family has been reported to be involved in a variety of human malignant tumours. However, little is known about their expression and prognostic value in human pancreatic cancer. Therefore, we performed a detailed cancer versus normal differential analysis.

Methods: The Cancer Genome Atlas (TCGA) and Gene Expression Profiling Interactive Analysis (GEPIA) databases were used to analyse the mRNA expression levels of the IGF2BP family in various cancers, including pancreatic cancer. Then, the LinkedOmics and GEPIA databases were used to assess the relation between the expression levels of IGF2BPs and overall survival (OS). Then, univariate and multivariate Cox regression analyses were performed, and subgroups based on grade and stage were analysed. The signalling pathways associated with IGF2BP2 and IGF2BP3 were then investigated via gene set enrichment analysis (GSEA).
\end{abstract}

Results: IGF2BP2 and IGF2BP3 were associated with each subset of OS based on grade and stage. Further clinical correlation analysis of IGF2BP2 and IGF2BP3 confirmed that IGF2BP2 and IGF2BP3 are fundamental factors in promoting pancreatic cancer progression.

Conclusion: IGF2BP2 and IGF2BP3 are key factors in promoting the progression of pancreatic cancer and are closely related to overall survival.

Keywords: Pancreatic Cancer, Expression, Prognosis, IGF2BP, Bioinformatic

\section{Background}

Pancreatic cancer is a high-mortality tumour with a fiveyear overall survival rate of approximately $7 \%[1,2]$. Among the causes of cancer-related death, this malignant tumour ranks fourth in the United States and sixth in China $[1,3]$. Approximately $80 \%$ of patients with pancreatic cancer have dissemination at the time of diagnosis $[1,4]$. These patients have lost the chance for radical treatment of pancreatic cancer. In the past decade,

\footnotetext{
*Correspondence: zcfmlm@163.com; qinxihu@yeah.net

'Department of General Surgery, the Affiliated Changzhou No. 2 People's Hospital of Nanjing Medical University, 68 Pohu Middle Road, Changzhou, Jiangsu 213000, P.R. China

Full list of author information is available at the end of the article
}

despite advancements in anti-metabolism therapy and targeted therapy, the overall survival rate of patients has not significantly improved due to the late pathological stage, high invasive phenotype and chemotherapy resistance.

Insulin-like growth factor 2-mRNA binding proteins (IGF2BPs), also known as IGF-II mRNA binding proteins (IMPs), are encoded by different genes that belong to the regulatory RNA binding protein family and are involved in the localization of their target RNA, stability and translation control [5]. As the names of these proteins indicate, they are recognized members of the IGF axis that can be linked to IGF2 transcripts $[6,7]$. To

(c) The Author(s). 2020 Open Access This article is licensed under a Creative Commons Attribution 4.0 International License, which permits use, sharing, adaptation, distribution and reproduction in any medium or format, as long as you give appropriate credit to the original author(s) and the source, provide a link to the Creative Commons licence, and indicate if changes were made. The images or other third party material in this article are included in the article's Creative Commons licence, unless indicated otherwise in a credit line to the material. If material is not included in the article's Creative Commons licence and your intended use is not permitted by statutory regulation or exceeds the permitted use, you will need to obtain permission directly from the copyright holder. To view a copy of this licence, visit http://creativecommons.org/licenses/by/4.0/ The Creative Commons Public Domain Dedication waiver (http://creativecommons.org/publicdomain/zero/1.0/) applies to the data made available in this article, unless otherwise stated in a credit line to the data. 
date, insulin-like growth factor 2 mRNA binding proteins, including IGF2BP1 (IMP1), IGF2BP2 (IMP2), and IGF2BP3 (IMP3), are a unique family of m6A readers that target the common $\mathrm{m} 6 \mathrm{~A}$ sequence by recognizing thousands of mRNA transcripts [8]. In mammals, the protein domains of the three members of the IGF2BP protein family are strikingly similar. All three members of the protein family contain two N-terminal RRMs and four C-terminal hnRNPK homology $(\mathrm{KH})$ domains. The latter are arranged in two dual domains $(\mathrm{KH} 1+2$ and $\mathrm{KH} 3+4)$ [9]. Consistent with the conservation of six potential RNA binding domains, all three IGF2BPs bind to single-stranded RNA in vitro and in vivo [9-11]. However, the role of the entire IGF2BP family in pancreatic cancer remains controversial. Therefore, it was necessary to probe the role of the IGF2BP family in pancreatic cancer.

The Cancer Genome Atlas (TCGA) is considered to be the largest cancer database, containing more than 20 , 000 primary cancer samples and normal matched samples for multiple cancer types. Therefore, we can use bioinformatics methods to study tumour data more deeply. To evaluate the relationship between the IGF2BP family and pancreatic cancer progression, we analysed mRNA expression in pancreatic cancer samples from the TCGA with $\mathrm{R}$ software and verified it in patients.

\section{Methods}

\section{GEPIA dataset}

Gene Expression Profiling Interactive Analysis (GEPIA) is a new web-based tool for gene expression analysis between tumour and normal data from The Cancer Genome Atlas (TCGA) and the Genotype-Tissue Expression (GTEx) project, applying a standard processing pipeline. It provides customizable functions such as tumour and normal differential expression analysis, and we can demonstrate the expression of IGF2BP1-3 in pancreatic cancer and normal tissues. GEPIA possesses key variable and interactive functions, including profile plotting, differential expression analysis, patient survival analysis, similar gene detection and dimensionality reduction analysis.

\section{LinkedOmics dataset}

LinkedOmics is a new and unique tool in the software ecosystem for disseminating data from all 32 TCGA cancer types. It can be used to access, analyse, and compare multiomics data within and across tumour types. We performed a prognostic analysis for the IGF2BP gene family using the LinkedOmics pancreatic cancer dataset.

TCGA data acquisition and differentially expressed IGF2BP gene analysis

The pancreatic cancer data in the TCGA contains 178 pancreatic cancer samples with important information, including pathological grade and clinical stage. All mRNA expression data, along with clinical data, were downloaded and further analysed with $\mathrm{R}$ software.

We utilized the "limma" package in $\mathrm{R}$ software to normalize the original expression levels of mRNAs downloaded from the TCGA. The "limma" package was used to analyse the expression of each IGF2BP gene between every grade and stage of cancer tissues. Last, a $P$ value $<0.05$ was set as the filter condition for differentially expressed IGF2BP.

\section{Gene set enrichment analysis of pancreatic cancer}

Performed gene enrichment analysis (version 3.0, the broad Institute of MIT and Harvard, http://software. broadinstitute.org/gsea/downloads.jsp) between pancreatic cancer and normal tissues to study the biological pathways of pancreatic cancer. Specifically, set "collapse data set to gene symbols" to false, set the number of marks to 1000 , set the "permutation type" to phenotype, set the "enrichment statistic" to weighted, and utilized the Signal2Noise metric to rank genes. The high expression group was taken as the experimental group, and the low expression group was taken as the reference group. The "c2.cp.kegg.v7.0.symbols.gmt" gene set database was utilized for enrichment analysis. Cut-off criteria including gene set size $>500$ and $<15$, FDR $<0.25$, and nominal $P$-value $<0.05$.

\section{Functional enrichment analyses of pancreatic cancer}

Kyoto Encyclopedia of Genes and Genomes (KEGG) and Gene Ontology (GO) functional enrichment analyses were performed to analyse IGF2BP2 and IGF2BP3. The Database for Annotation, Visualization, and Integrated Discovery (DAVID, https://david.ncifcrf.gov/) was applied to identify enriched KEGG and GO pathways and terms.

\section{Cell lines and reagents}

The human pancreatic cancer cell lines, including ASPC-1, SW1990, PANC-1, MIA Paca-2 and HPDE6C7, were purchased from the University of Colorado Cancer Center Cell Bank. ASPC-1, PANC-1, MIA Paca2 and HPDE6-C7 cells were cultured in DMEM medium with $10 \%$ FBS (Invitrogen, Carlsbad, CA, USA) at $37^{\circ} \mathrm{C}$ in a $5 \% \mathrm{CO}_{2}$ atmosphere. SW1990 cells were cultured in RPMI 1640 medium supplemented with 10\% FBS (Invitrogen, Carlsbad, CA, USA) at $37^{\circ} \mathrm{C}$ in a $5 \% \mathrm{CO}_{2}$ atmosphere. Cells were digested and passaged when cell confluence reached $80-90 \%$.

\section{Quantitative reverse transcription polymerase chain reaction}

Total RNA was extracted from the ASPC-1, SW1990, PANC-1, MIA Paca-2 and HPDE6-C7 cell lines using TRIzol reagent (Life Technologies) according to the 


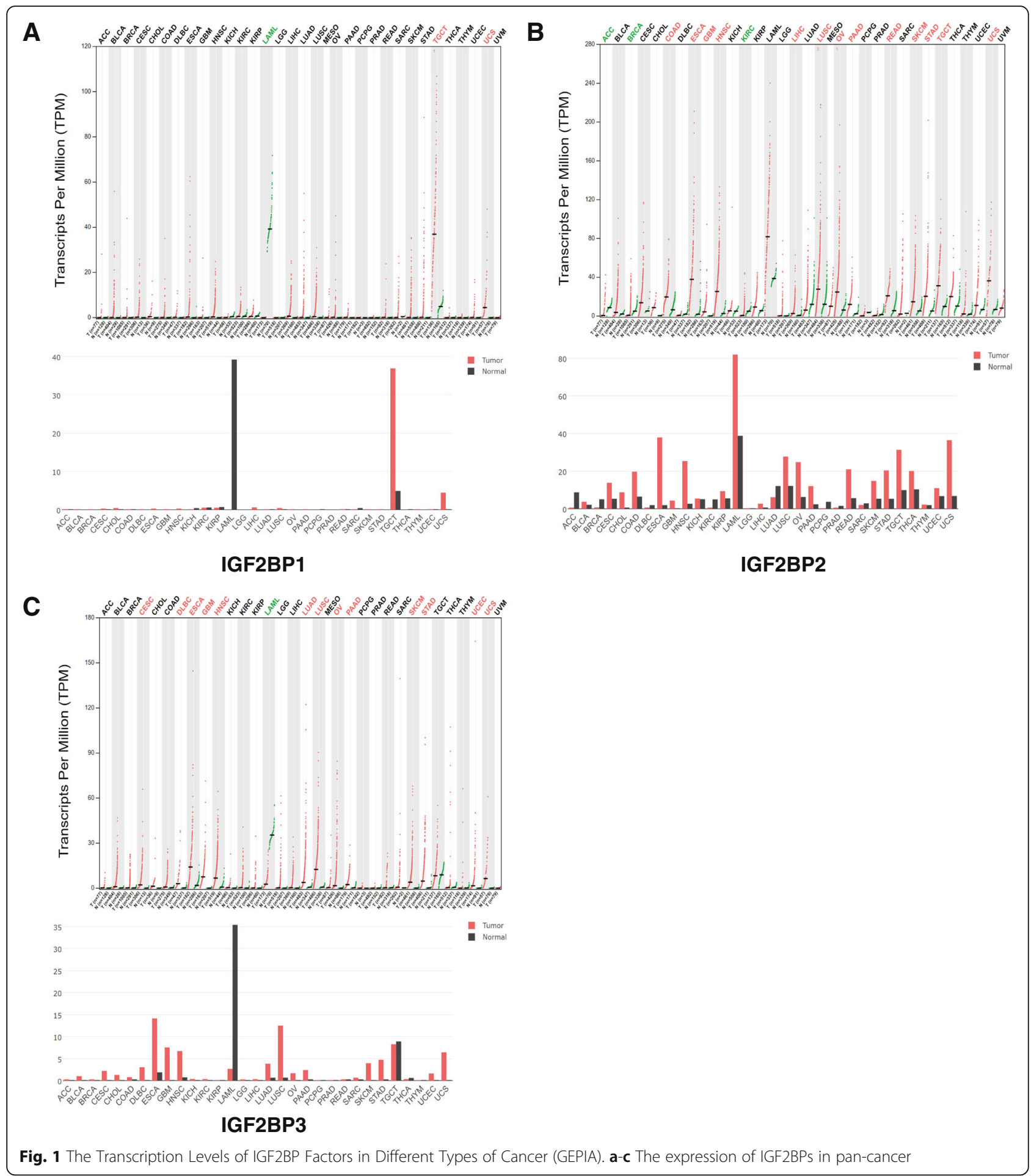

instructions provided by the manufacturer. Total RNA $(1 \mu \mathrm{g})$ was used as a template to synthesize complementary DNA (cDNA) using a PrimeScript RT Reagent Kit with cDNA Eraser (Takara Biotechnology). Subsequently, qRT-PCR was performed using SYBR Premix Ex Taq (Takara Bio Inc.). The primer sequences used for real-time PCR are listed in Table S1. All qRT-PCR assays were performed on an ABI 7900 system (Applied Biosystems).

\section{Cell proliferation assay}

The Cell Counting Kit-8 (CCK-8) assay (MedChemExpress) was used according to the protocol provided by the manufacturer to assess cell proliferation. ASPC-1 
and SW1990 cells were seeded into 96 -well plates $(5 \times$ $10^{3}$ cells/plate) and cultured at $37^{\circ} \mathrm{C}$. Ten microlitres of CCK- 8 solution was added to each well of the plate at the following times: $0 \mathrm{~h}, 24 \mathrm{~h}, 48 \mathrm{~h}, 72 \mathrm{~h}$ and $96 \mathrm{~h}$. Optical density (OD) was measured at 1-4 days at a wavelength of $450 \mathrm{~nm}$ using a Multiskan FC microplate reader (Thermo Fisher Scientific, Inc.).

\section{Protein extraction and Western blot analysis}

Utilized RIPA lysis buffer with $1 \%$ phenylmethanesulfonyl fluoride (PMSF) and DL-dithiothreitol (DTT) to extracted total protein. The BCA protein assay kit (Beyotime Biotechnology) was used to determine the concentration of the protein lysate. Equivalent $(30 \mu \mathrm{g})$ protein was isolated by $10 \%$ SDS-PAGE. Then, the proteins were transferred to PVDF membranes $(0.45 \mathrm{~mm}$; Beijing Solarbio Science \& Technology Co., China). Before incubated the membranes with IGF2BP2 and IGF2BP3 antibodies (1:1000, R\&D Systems, MN, USA) at $4{ }^{\circ} \mathrm{C}$ for $12 \mathrm{~h}$, the membranes were blocked at room temperature with $5 \%$ BSA for $1 \mathrm{~h}$. Then GAPDH rabbit polyclonal antibody (1:4000, Proteintech, USA) was utilized as a loading control for normalization. HRPconjugated secondary anti-rabbit antibody (1:4000; ProteinTech Group) was incubated at room temperature about $1 \mathrm{~h}$. Finally, the bands were placed on an Omega Lum G machine (Aplegen, USA) and visualized using ECL reagents (Thermo Fisher Scientific).

\section{Colony formation assay}

SW1990 cells were seeded into 6-well plates $\left(1 \times 10^{3}\right.$ cells/plate) and cultured for 14 days. Then, cells were fixed with $10 \%$ formaldehyde for $5 \mathrm{~min}$ and stained with $1 \%$ crystal violet for $30 \mathrm{~s}$ prior to counting the number of colonies.

\section{Cell invasion assay}

Cell invasion was performed with transwell plates (24well insert, $8 \mu \mathrm{m}$ pore size; BD Biosciences, Bedford, MA, USA). The filters (Corning Inc., USA) were covered with $55 \mu \mathrm{L}$ of Matrigel (1:8 dilution; BD Biosciences).
Then, $5 \times 10^{4}$ SW1990 cells were distributed in $100 \mu \mathrm{l}$ of serum-free RPMI-1640 medium and inoculated into the upper chamber. Next, $600 \mu \mathrm{l}$ of 90\% RPMI-1640 medium supplemented with 10\% FBS was added to the bottom chamber. After $24 \mathrm{~h}$ of incubation, the chamber was fixed with $4 \%$ paraformaldehyde for $30 \mathrm{~min}$ and then stained with $0.1 \%$ crystal violet for $30 \mathrm{~min}$. Finally, magnification microscope to count the number of invading cells in the bottom chamber.

\section{Statistical analysis}

In this study, the experiments were carried out in triplicate, and the data were expressed as the mean \pm standard deviation. The t-test was utilized for the statistical analysis of the data. Comparisons between multiple groups were performed with one-way ANOVA followed by an LSD-t test. $P<0.05$ was considered significant.

\section{Results}

\section{Transcriptional levels of IGF2BPs in patients with pancreatic Cancer}

Three IGF2BP factors were identified in mammalian cells, and the expression levels of the IGF2BPs in various cancers were compared via the GEPIA database. The IGF2BP1 mRNA expression level was not upregulated in pancreatic cancer, but the IGF2BP2 and IGF2BP3 mRNA expression levels were upregulated in pancreatic cancer to varying degrees (Fig. 1).

The GEPIA database was utilized to further analyse whether there was a difference in the expression of IGF2BP factors between pancreatic cancer and normal pancreatic tissues. According to ONCOMINE, the expression of IGF2BP1 in pancreatic cancer tissue was not significantly different from that in normal pancreatic tissue. However, in the pancreatic cancer datasets described by Segara, Pei, and Badea, IGF2BP2 was overexpressed in pancreatic carcinoma tissue compared with normal tissue, with fold changes of 3.446, 2.657, and 2.01, respectively (Table 1) [12-14]. Regarding IGF2BP3, all four pancreatic cancer datasets indicated

Table 1 The Significant Changes of IGF2BP Expression in Transcription Level between Different Types of Pancreatic Cancer (ONCOMINE Database)

\begin{tabular}{llllll}
\hline Gene ID & Types of Pancreatic Cancer versus Norma & Fold Change & $\boldsymbol{p}$ Value & t Test & References \\
\hline IGF2BP2 & Pancreatic Carcinoma versus Normal & 3.446 & $1.90 \mathrm{E}-06$ & 7.957 & Segara Pancreas Statistics [12] \\
& Pancreatic Carcinoma versus Normal & 2.657 & $1.93 \mathrm{E}-07$ & 6.193 & Pei Pancreas Statistics [13] \\
& Pancreatic Ductal Adenocarcinoma versus Normal & 2.01 & $5.63 \mathrm{E}-09$ & 6.407 & Badea Pancreas Statistics [14] \\
IGF2BP3 & Pancreatic Carcinoma versus Normal & 9.327 & $4.11 \mathrm{E}-12$ & 9.295 & Pei Pancreas Statistics [13] \\
& Pancreatic Ductal Adenocarcinoma versus Normal & 3.528 & $1.61 \mathrm{E}-08$ & 6.643 & Badea Pancreas Statistics [14] \\
& Pancreatic Ductal Adenocarcinoma versus Normal & 2.355 & 0.005 & 2.725 & Ishikawa Pancreas Statistics [15] \\
& Pancreatic Ductal Adenocarcinoma Epithelia versus Normal & 5.606 & 0.007 & 2.703 & Grutzmann Pancreas Statistics [16] \\
\hline
\end{tabular}


overexpression in both pancreatic carcinoma and pancreatic ductal adenocarcinoma (Table 1) [12-16].

\section{Expression levels of IGF2BPs in normal and pancreatic} Cancer tissues

We utilized the TCGA database to compare the expression levels of the IGF2BP family in normal pancreatic and pancreatic cancer tissues. Among the family members, the expression levels of IGF2BP2 and IGF2BP3 were significantly increased in pancreatic cancer tissues (Fig. 2a). With the GEPIA (Gene Expression Profiling Interactive Analysis) dataset (http://gepia.cancer-pku.cn/ ), we compared the mRNA expression levels of the members of the IGF2BP protein family between pancreatic cancer and normal tissues. The results showed that the expression of the IGF2BP1 gene in pancreatic cancer tissue was not different from that in normal pancreatic tissue. However, the expression levels of IGF2BP2 and

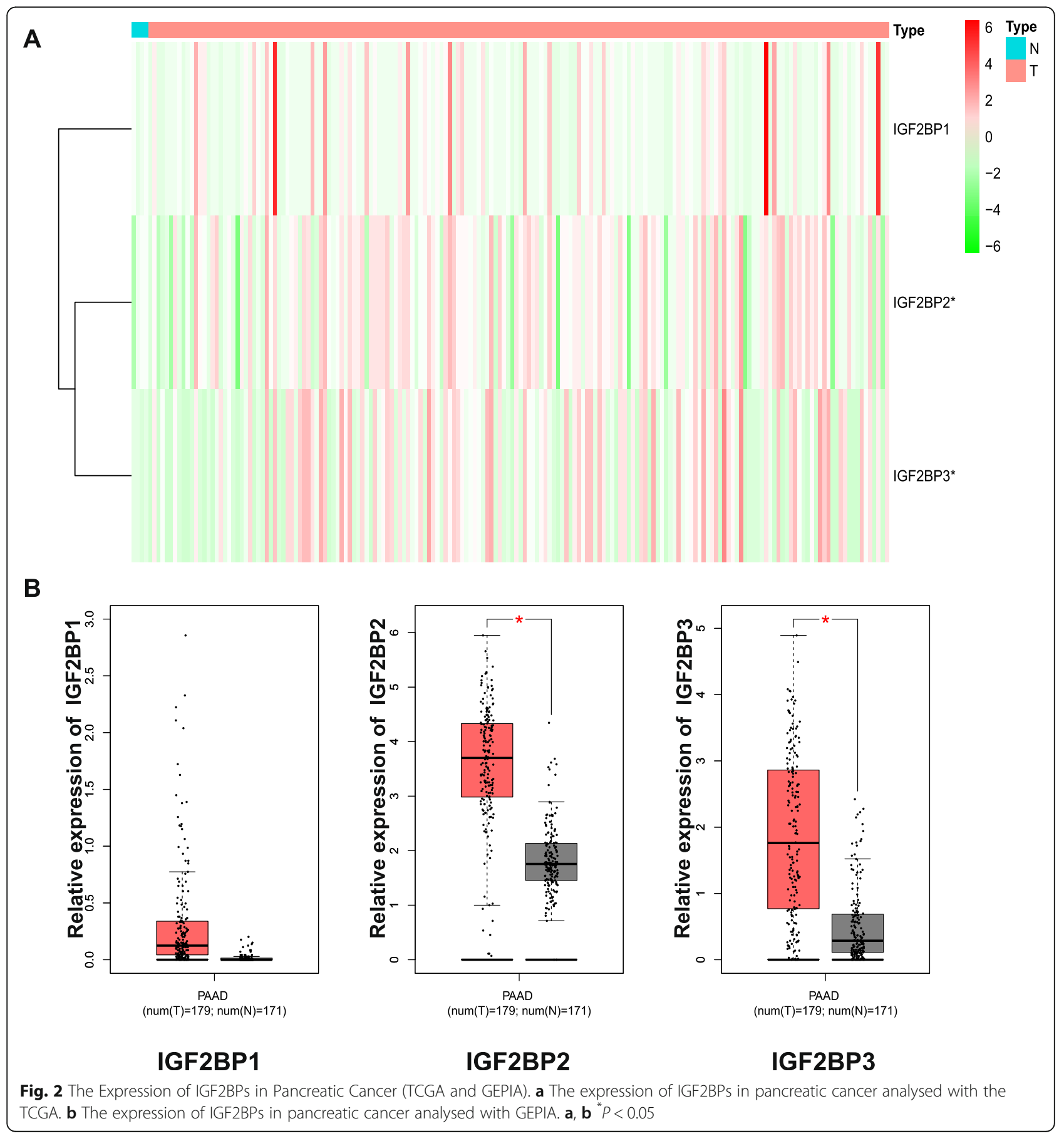


IGF2BP3 were higher in pancreatic cancer tissue than in normal pancreatic tissue (Fig. 2b).

\section{Clinical correlation analysis in pancreatic Cancer patients}

Furthermore, we performed a prognostic analysis of IGF2BP1, IGF2BP2, and IGF2BP3 in pancreatic cancer with the LinkedOmics and GEPIA datasets. In the LinkedOmics dataset, the high expression of IGF2BP1, IGF2BP2, and IGF2BP3 was significantly associated with the poor overall survival of pancreatic cancer patients (Fig. 3a). Interestingly, regarding IGF2BP1 and IGF2BP2, consistent results were obtained from the prognostic analysis of the GEPIA dataset (Fig. 3b).

The association between IGF2BP1-3 and each subset based on grade and stage was analysed with $\mathrm{R}$ software via the Wilcox test. A $P$-value $<0.05$ was considered statistically significant. We found that the expression levels of IGF2BP2 and IGF2BP3 continuously increased in each subgroup of grade except for grade 4 (Fig. 4a). Concerning the clinical stage, IGF2BP1-3 gradually increased in each subgroup, but there was no significant difference (Fig. 4b).

\section{Univariate and multivariate cox regression analyses}

Cox's proportional hazards model was applied to analyse related factors that may affect the overall survival of pancreatic cancer patients, in which IGF2BP2 and IGF2BP3 were identified as independent prognostic factors (Fig. 5a, b). In both univariate and multivariate analyses, low expression of IGF2BP2 and 3 suggested improved OS. In the multivariate analysis, the $\mathrm{HR}$ of IGF2BP2 was 1.415 , with a $95 \%$ CI of $1.133-1.768$, and the HR of IGF2BP3 was 1.052, with a 95\% CI of $1.017-$ 1.019. Furthermore, based on the results of the multivariate Cox regression analysis, we established a nomogram model that may predict patient survival (Fig. 5c).

\section{Gene mutation information}

cBioPortal was utilized to calculate the gene mutation rate in pancreatic cancer samples from the TCGA
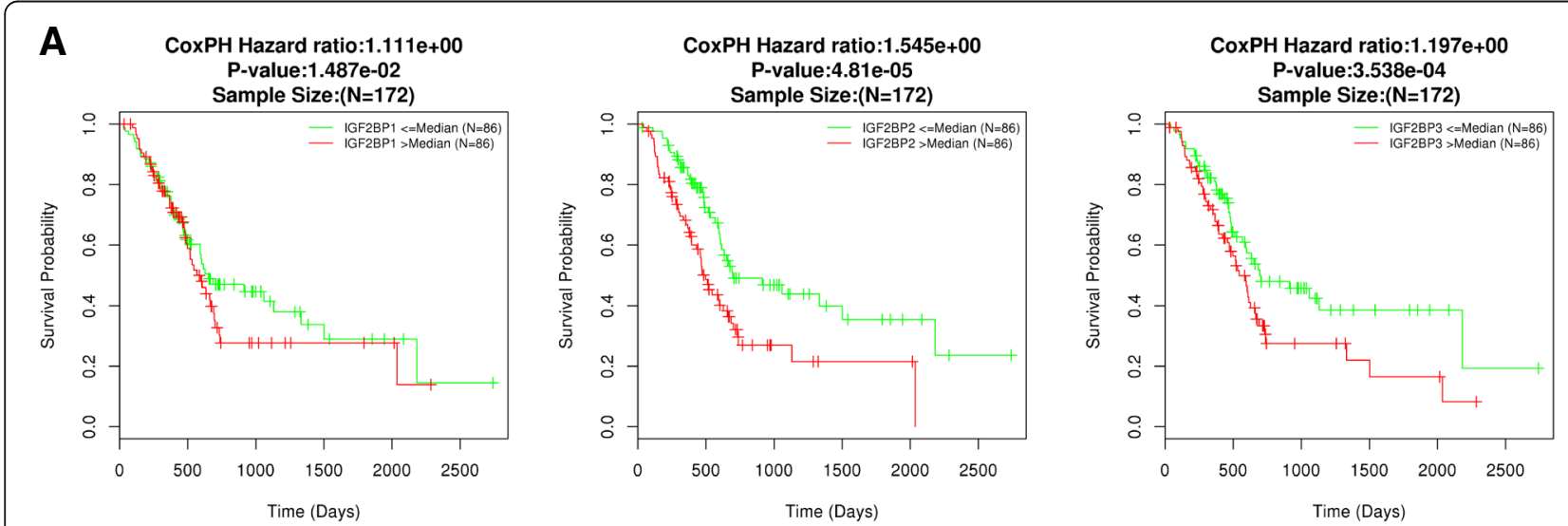

\section{B}
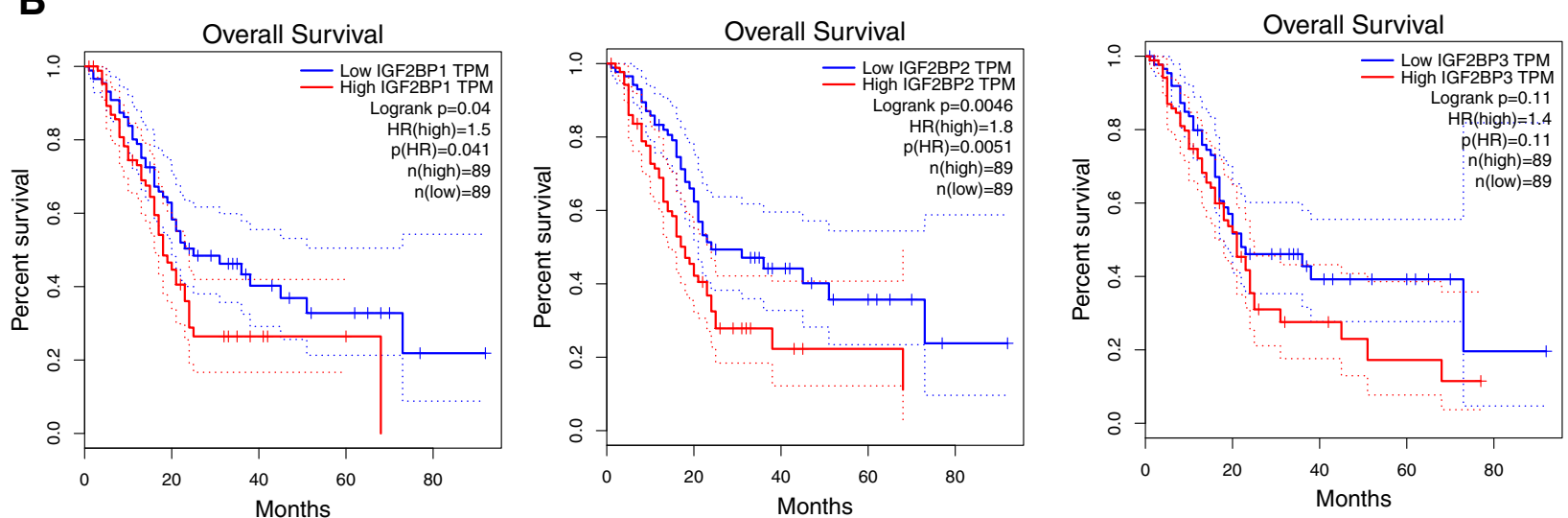

Fig. 3 The Prognostic Value of the mRNA Levels of IGF2BP Factors in Pancreatic Cancer Patients (LinkedOmics and GEPIA). a The prognostic value of the mRNA levels of IGF2BP factors in pancreatic cancer patients analysed with LinkedOmics. $\mathbf{b}$ The prognostic value of the mRNA levels of IGF2BP factors in pancreatic cancer patients analysed with GEPIA 


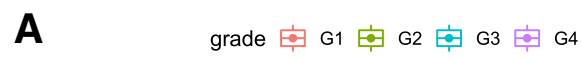

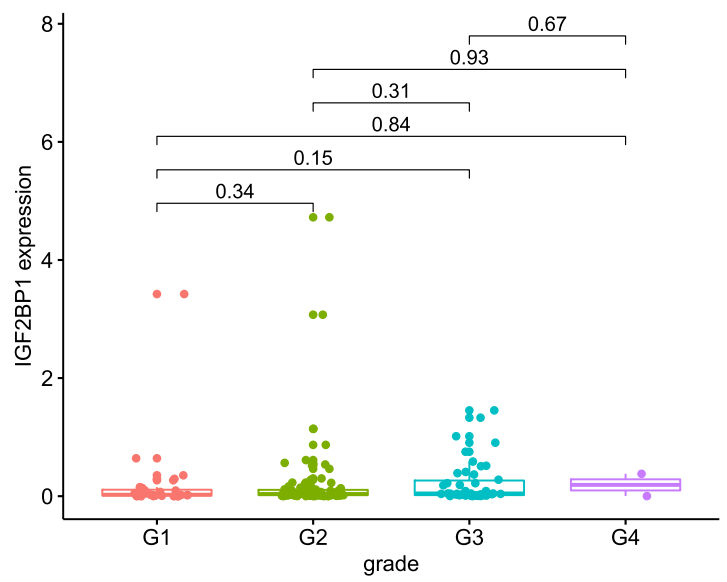

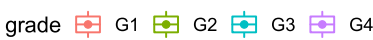

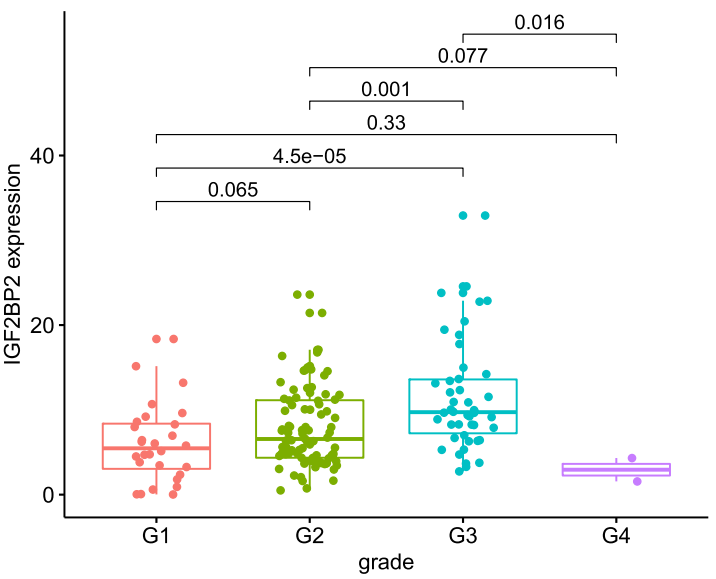

grade G1 G2 G3

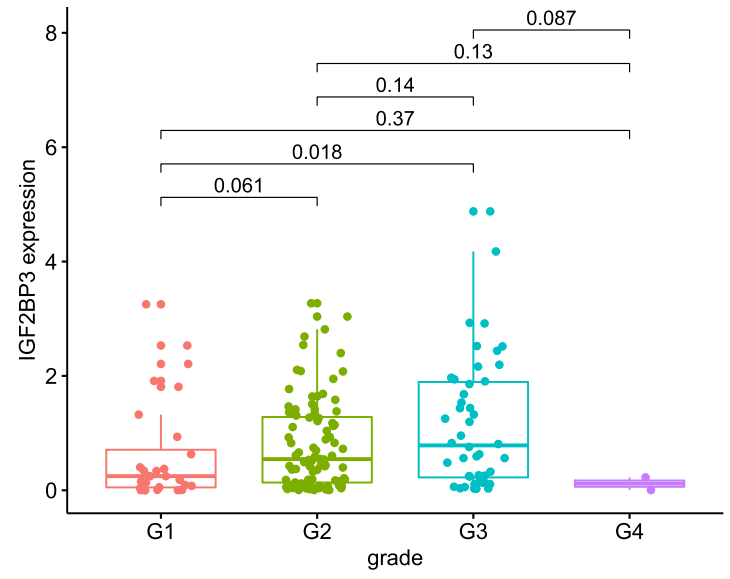

B stage 亩 StageI 自 Stagell 自 Stage III 宣 Stage IV

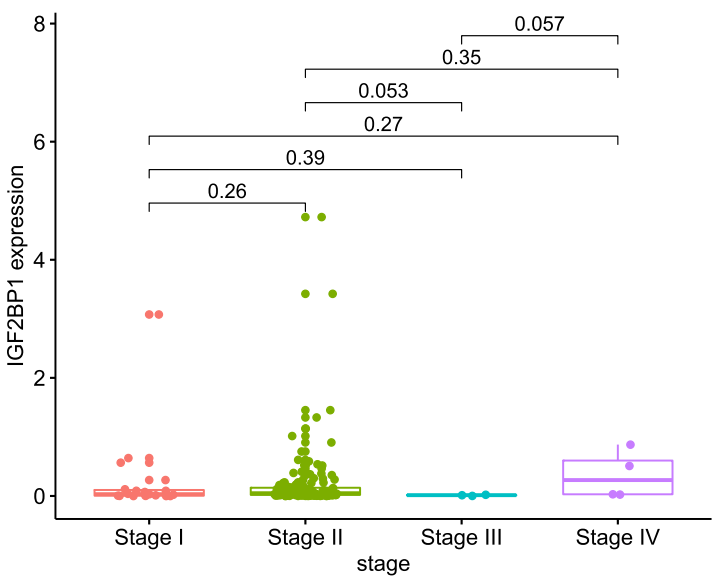

stage

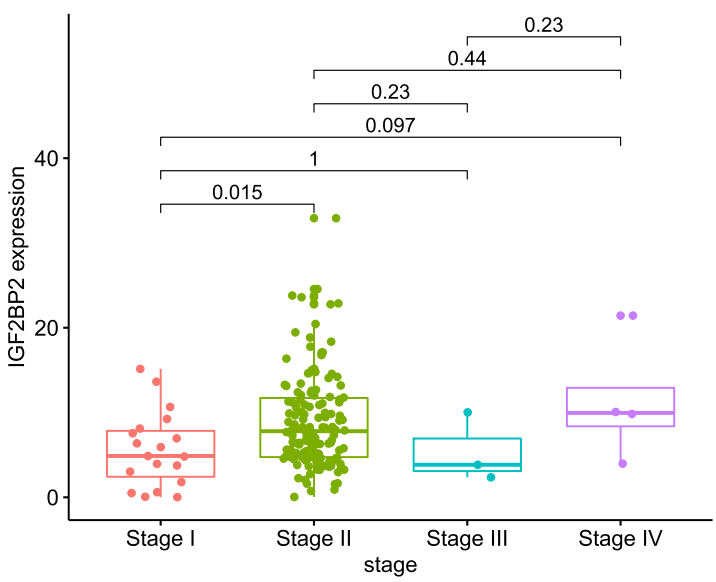

stage

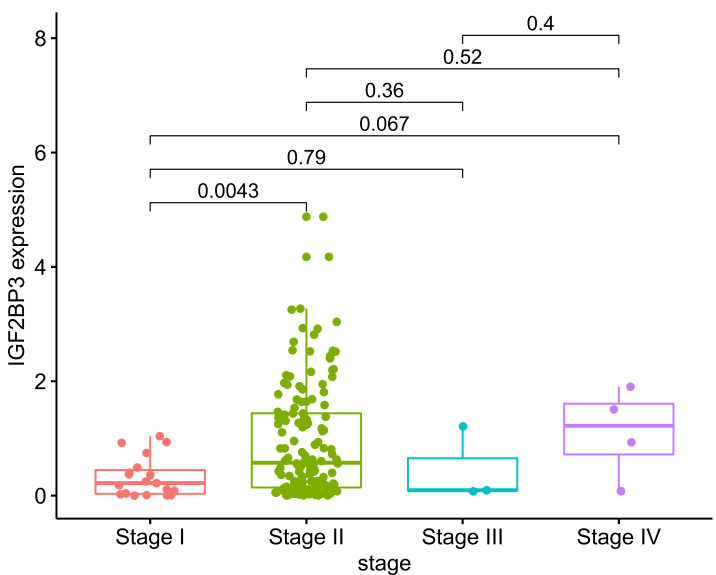

Fig. 4 Correlation analysis between grade and stage and IGF2BP1-3 expression in 178 pancreatic cancer samples. a Correlation analysis between pathological grade and IGF2BP1-3 expression in 178 pancreatic cancer samples. b Correlation analysis between clinical stage and IGF2BP1-3 expression in 178 pancreatic cancer samples 


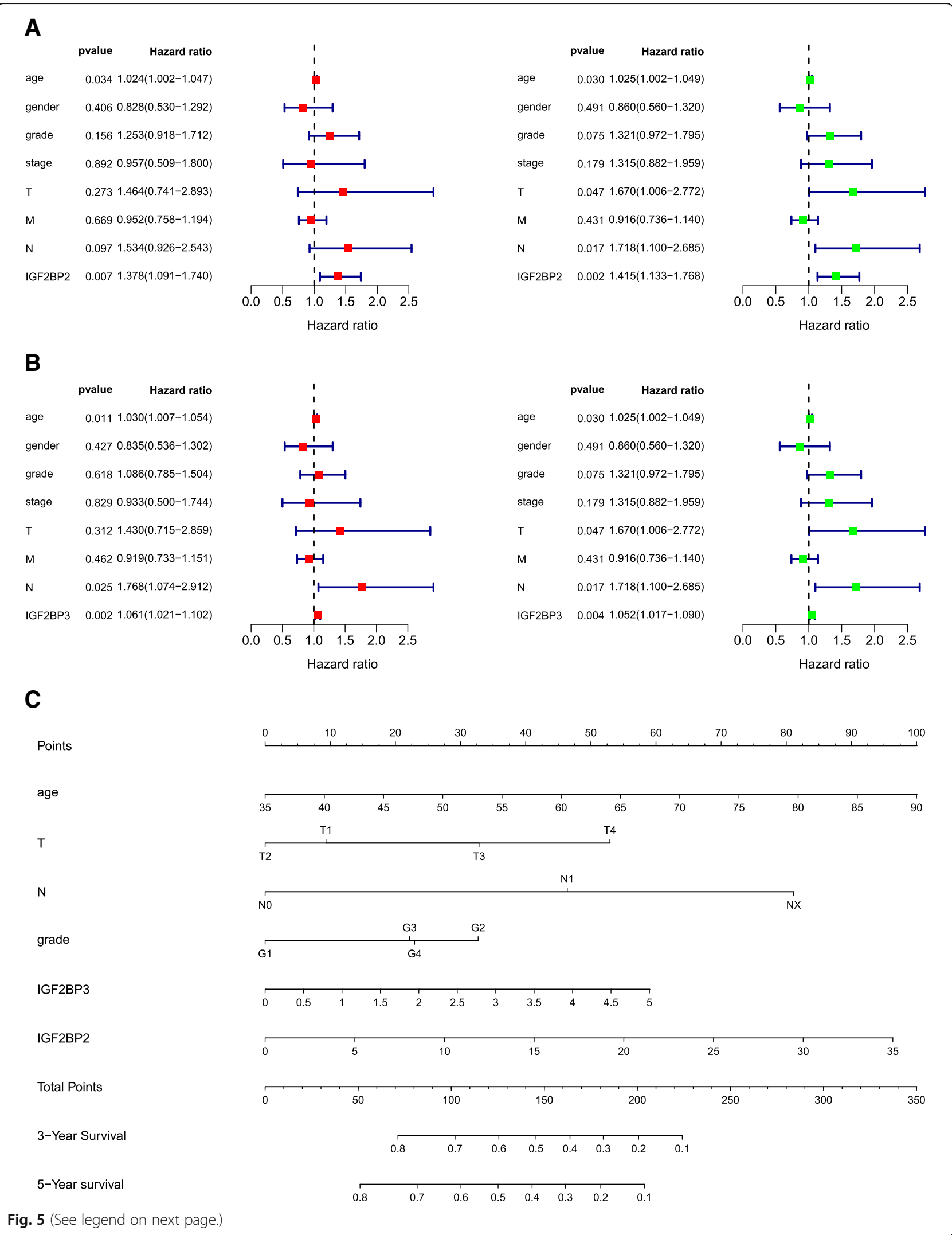


(See figure on previous page.)

Fig. 5 Cox's proportional hazards model of correlative factors in Pancreatic Cancer Patients. a Univariate and multivariate Cox regression analyses of eight factors (age, sex, grade, stage, T classification, M classification, N classification and IGF2BP2) affecting overall survival. b Univariate and multivariate Cox regression analyses of eight factors (age, sex, grade, stage, T classification, M classification, N classification and IGF2BP3) affecting overall survival. c An established nomogram to predict the survival of pancreatic cancer patients based on the Cox model

database. In general, missense mutations were the most frequent mutation type in pancreatic cancer. Collectively, SNP and C > T were confirmed to be the most fundamental variant type and SNV class, respectively. The median variation in each sample was approximately 26. Finally, we determined the top 10 mutated genes in pancreatic cancer as follows: TP53, KRAS, TTN, MUC16, SMAD4, CDKN2A, RYR1, RNF43, PCDH15 and ARID1A (Fig. 6a). Then, by performing a comparison with the top 10 mutation types, we determined the most frequent mutation types of IGF2BP1-3, which were missense mutations and silent mutations (Fig. 6b).

\section{Gene set enrichment analysis of IGF2BP2-3}

To fully understand the biological attributes of IGF2BP2 and IGF2BP3, we conducted gene set enrichment analysis. Based on the results of the GSEA, the top three upregulated enriched pathways associated with IGF2BP2 were as follows: adherens junction, pentose phosphate pathway and pentose and glucuronate interconversions. The principal downregulated biological pathways enriched in IGF2BP2 were as follows: primary bile acid biosynthesis, neuroactive ligand receptor interaction and glycosphingolipid biosynthesis ganglio series (Fig. 7a). The top three upregulated pathways associated with IGF2BP3 were as follows: pathogenic Escherichia coli infection, thyroid cancer and adherens junction. The principal downregulated biological pathways enriched in IGF2BP3 were as follows: glycine serine and threonine metabolism and neuroactive ligand receptor interaction (Fig. 7b).

\section{Gene functional enrichment analysis}

To fully understand the biological attributes of IGF2BP2 and IGF2BP3, we performed Kyoto Encyclopedia of Genes and Genomes (KEGG) and Gene Ontology (GO) analyses. We determined the biologically enriched genes, based on the results of DAVID, that are positively related to the expression levels of IGF2BP2 and IGF2BP3. In the $\mathrm{GO}$ analysis, the three biological processes in which genes positively related to IGF2BP2 expression are involved were as follows: regulation of cytoskeleton organization, neutrophil activation and neutrophil degranulation. The three cell components involved in these co-expressed genes were as follows: adherens junction, cell-substrate junction and focal adhesion. In addition, the three main molecular functions of these coexpressed genes were as follows: cell adhesion molecule binding, cadherin binding and actin binding (Fig. 8a). In the pathway analysis of genes that were positively related to IGF2BP2 expression, the top three enriched terms were as follows: salmonella infection, shigellosis and pathogenic Escherichia coli infection (Fig. 8a). In the GO analysis, the three biological processes in which genes positively related to IGF2BP3 expression are involved were as follows: viral life cycle, regulation of chromosome organization and regulation of mRNA metabolic process. The three cell components involved in these coexpressed genes were as follows: adherens junction, cellsubstrate junction and focal adhesion. In addition, the three main molecular functions of these co-expressed genes were as follows: cell adhesion molecule binding, cadherin binding and transcription coregulator activity (Fig. 8b). In the KEGG pathway analysis of genes that were positively related to IGF2BP2 expression, the top three enriched terms were as follows: human papillomavirus infection, endocytosis and salmonella infection (Fig. 8b). Finally, the GO and KEGG analyses of biologically enriched genes that were positively correlated with IGF2BP2 and IGF2BP3 expression revealed the top 10 relevant biological processes, including cell junction organization, salmonella infection, mitotic nuclear division, and cell cycle (Supplement Figure 1).

\section{IGF2BP2 and IGF2BP3 expression and function in cell lines}

To further explore IGF2BP2 and IGF2BP3 expression in cell clines, qPCR was performed. As expected, IGF2BP2 and IGF2BP3 proteins were significantly increased in pancreatic cancer cells compared with HPDE6-C7 cells, while the expression of IGF2BP2 and IGF2BP3 in pancreatic cancer cells was further increased (Fig. 9a, b). As predicted in the GSEA above, we inferred that IGF2BP2 and IGF2BP3 promote the proliferation or metastasis of pancreatic cancer cells to accelerate progression. The growth rates of pancreatic cancer cell lines transfected with IGF2BP2 siRNA and IGF2BP3 siRNA were significantly slower than that of cell lines transfected with the NC siRNA (Fig. 9c, d, e). In the cell invasion analysis, the knockdown of IGF2BP2 and IGF2BP3 significantly decreased the invasion rate of SW1990 cells (Fig. 9f).

\section{Discussion}

In the past few years, despite tremendous efforts in pancreatic cancer research, the 5-year patient survival rate has not improved significantly. Patients with early pancreatic cancer have a good prognosis and can be cured 
A

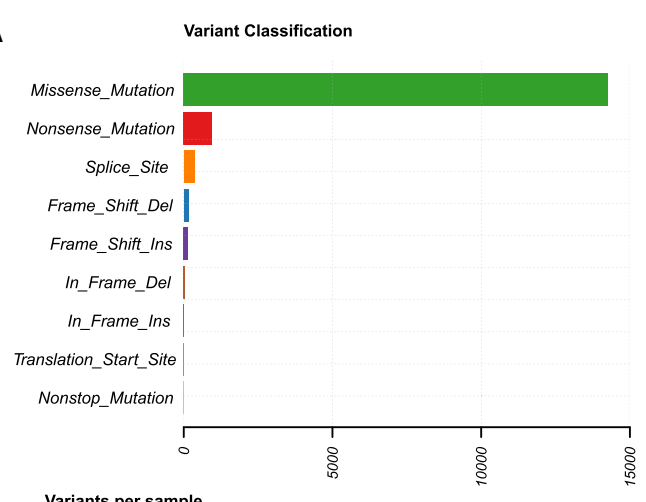

Variants per sample

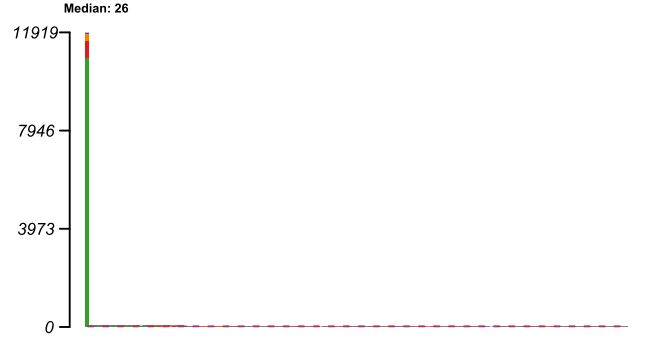

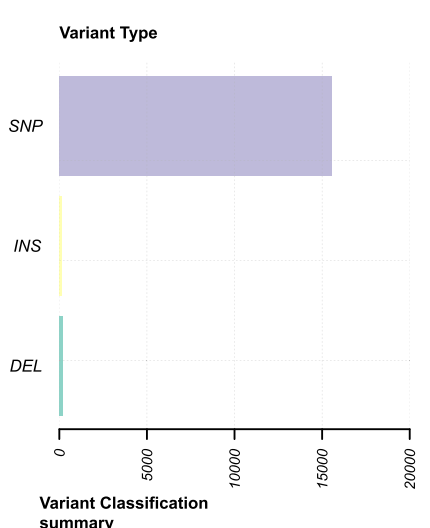

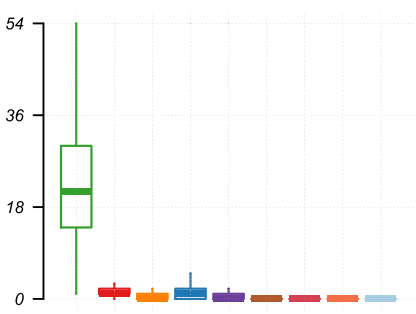

SNV Class

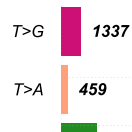

$\begin{array}{ll}T>C & 2394\end{array}$

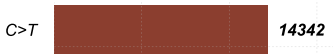

$C>G \quad 476$

$C>A$

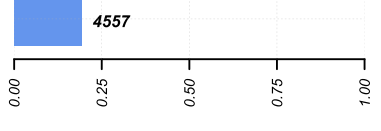

Top 10

mutated genes
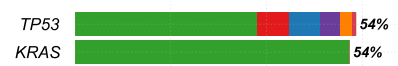

TTN

MUC16 $16 \%$

\begin{tabular}{l|l} 
SMAD4 & $17 \%$
\end{tabular}

\begin{tabular}{l|l} 
CDKN2A & $17 \%$
\end{tabular}

\begin{tabular}{l|l} 
RYR1 & $\mathbf{4} \%$
\end{tabular}

RNF43 $17 \%$

PCDH15 $\quad 4 \%$

ARID1A $\quad 4 \%$

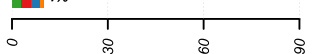

B
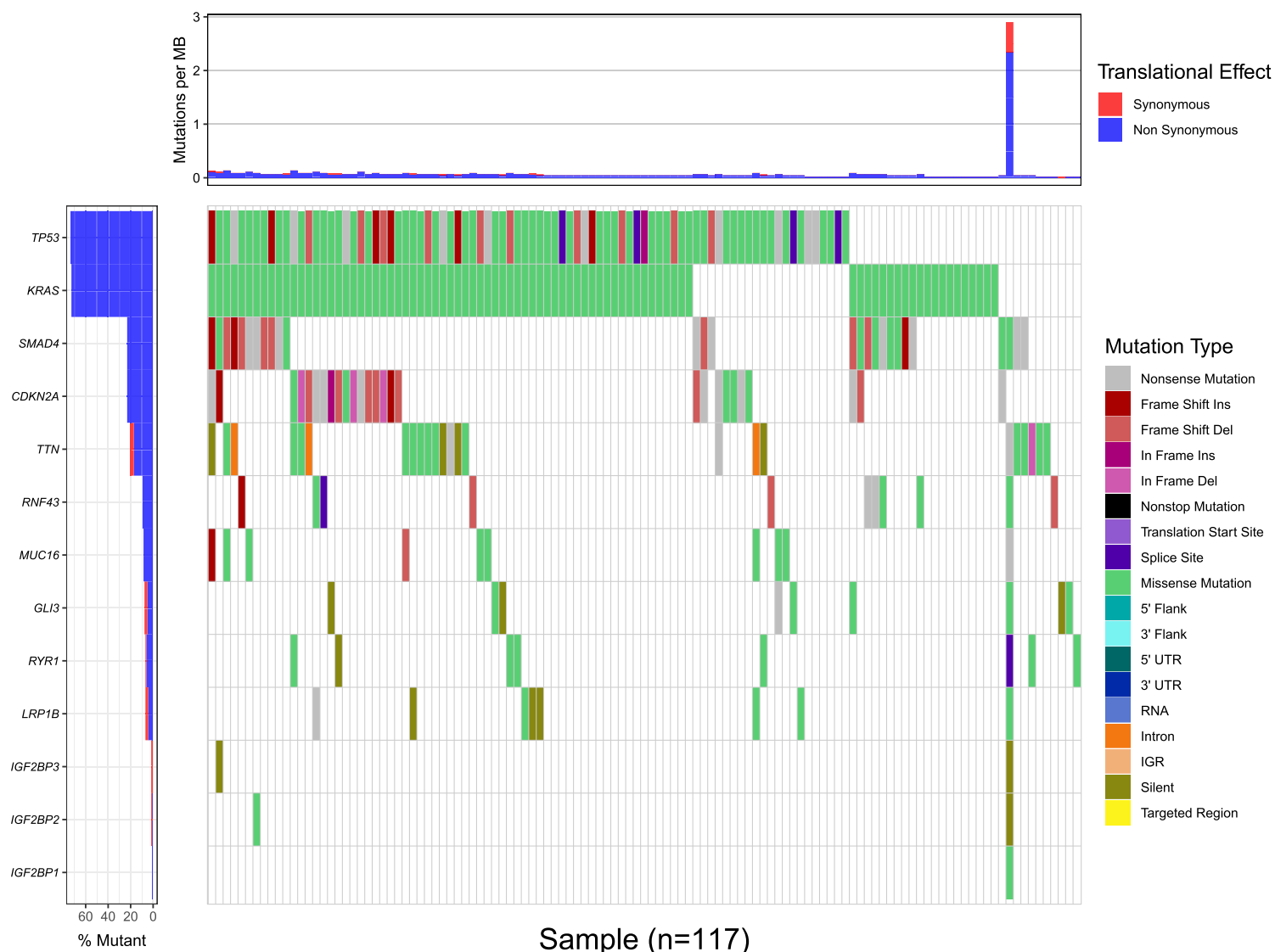

Mutation Type

Nonsense Mutation Frame Shift Ins Frame Shift Del In Frame Ins In Frame Del

Nonstop Mutation Translation Start Site Splice Site Missense Mutation

5' Flank

3' Flank

5' UTR

3' UTR

RNA

Intron

IGR

Silent

Targeted Region

Sample $(n=117)$

Fig. 6 (See legend on next page.) 
(See figure on previous page.)

Fig. 6 Information on gene mutations in pancreatic cancer. a Missense mutation was the most frequent mutation class in pancreatic cancer. SNP and C > T were confirmed to be the most fundamental variant type and SNV class, respectively. The median variation in each sample was approximately 26. The top 10 mutated genes in pancreatic cancer. $\mathbf{b}$ The mutation types of IGF2BP1-3 compared with the top 10 mutation types in pancreatic cancer

by surgery combined with adjuvant therapy. However, most patients with advanced pancreatic cancer cannot undergo surgical resection alone. For patients with advanced pancreatic cancer, it is essential to explore more effective prognostic markers and therapeutic targets. Therefore, we screened the IGF2BP protein family through bioinformatics and conducted a differential analysis. IGF2BP2 and IGF2BP3, which are related to pancreatic cancer progression and survival, were further analysed, and their functions were verified in vitro.

In the preliminary analysis, three members of the IGF2BP protein family were identified to have differential expression between pancreatic cancer and adjacent tissues. Further analysis confirmed that only IGF2BP2 and IGF2BP3 were associated with pancreatic cancer progression. Therefore, only IGF2BP2 and IGF2BP3

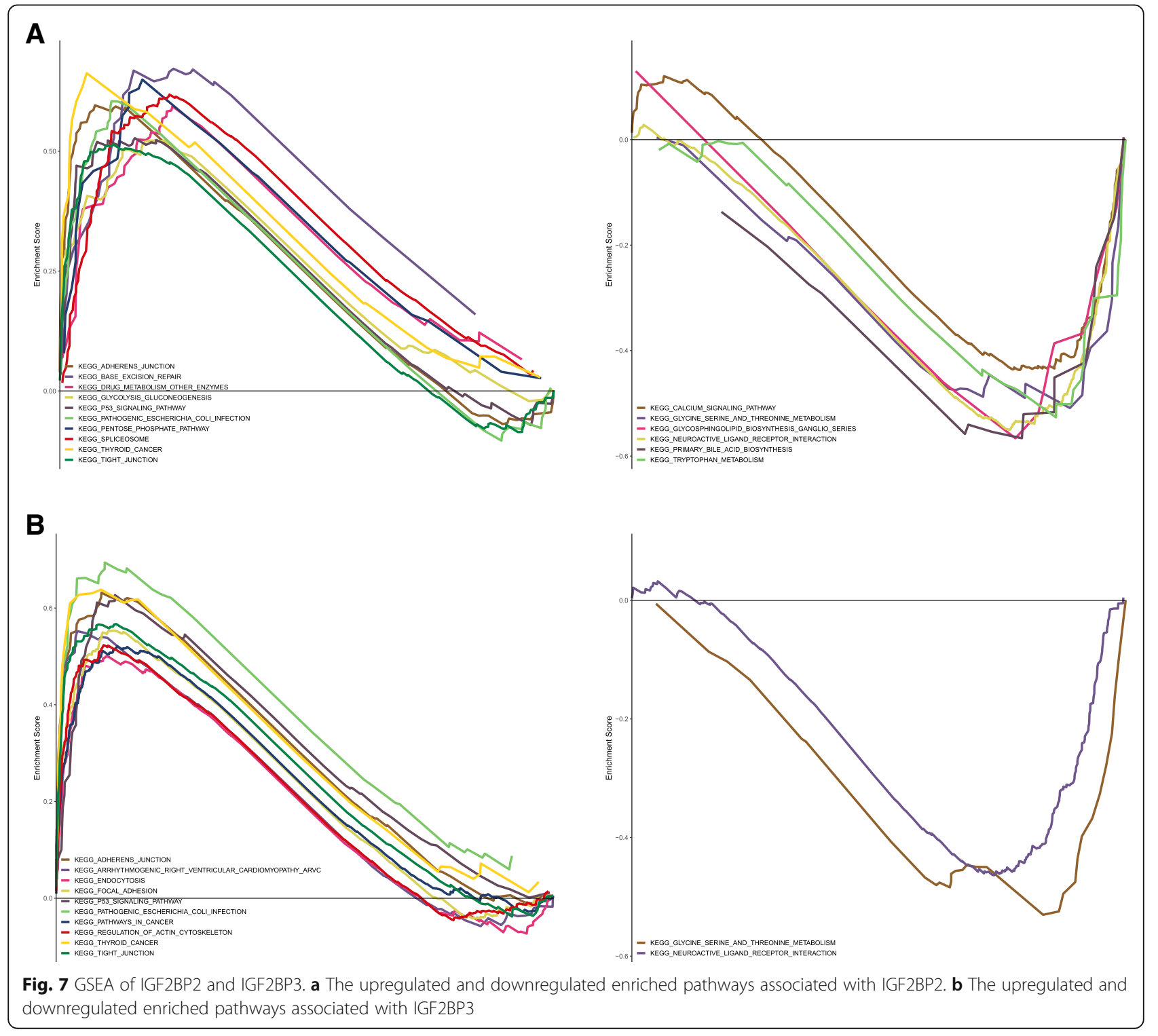




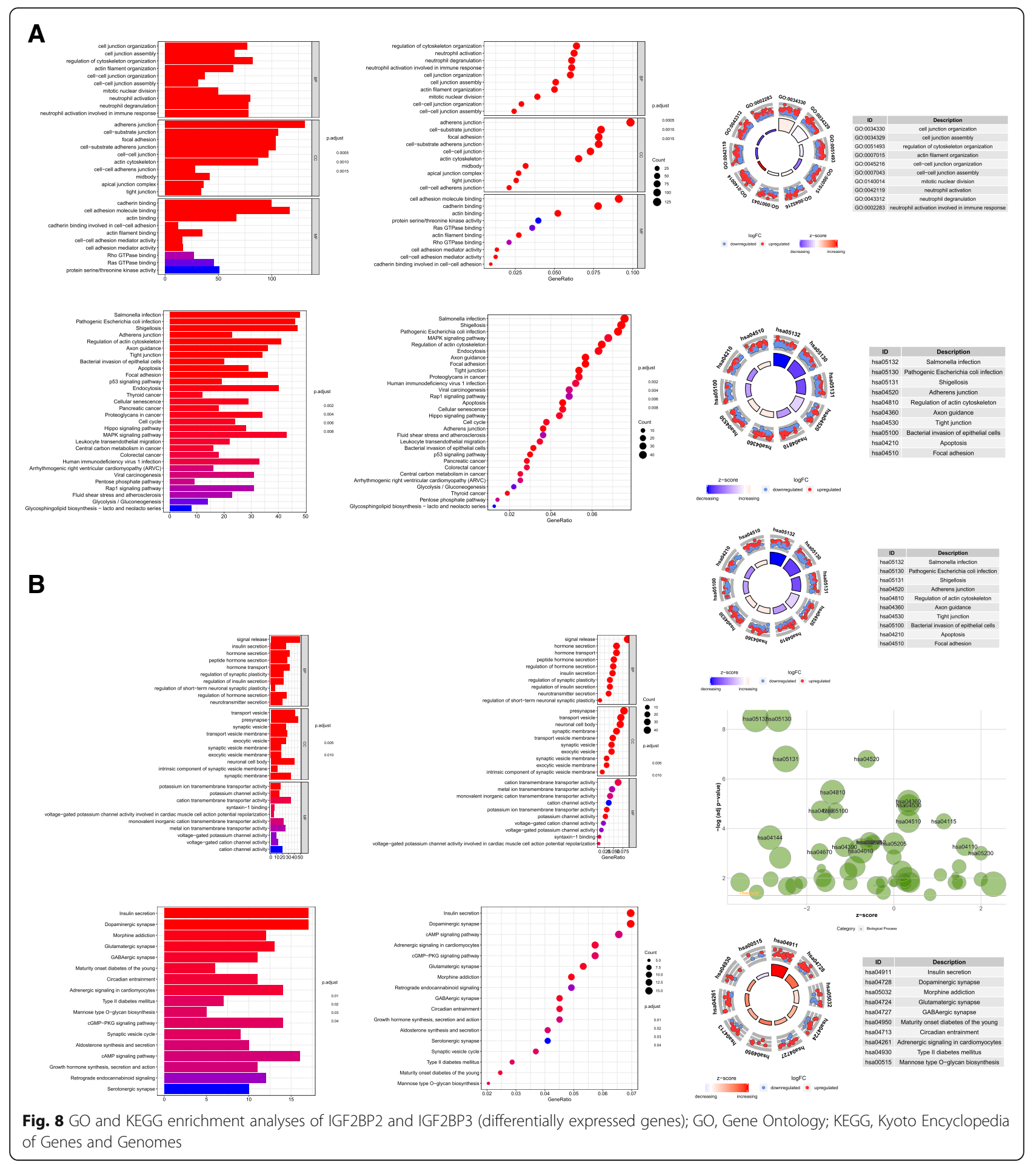

were subjected to gene enrichment analysis to assess their cell compositions, molecular functions and biological characteristics.

In the gene set enrichment analysis, the base excision repair (BER) pathway was determined to be the most relevant pathway for IGF2BP2. Notably, the BER pathway plays a significant role in maintaining genome integrity, and many human health issues occur when any part of the BER pathway is aberrant [17]. This pathway begins with glycosylation enzymes and recognizes and excises lesions through the cleavage of glycosidic bonds [17]. Dianov et al. verified that aberrant P53 signalling could lead to failure of the BER coordination mechanism, APE1 overexpression and genome instability [18]. 


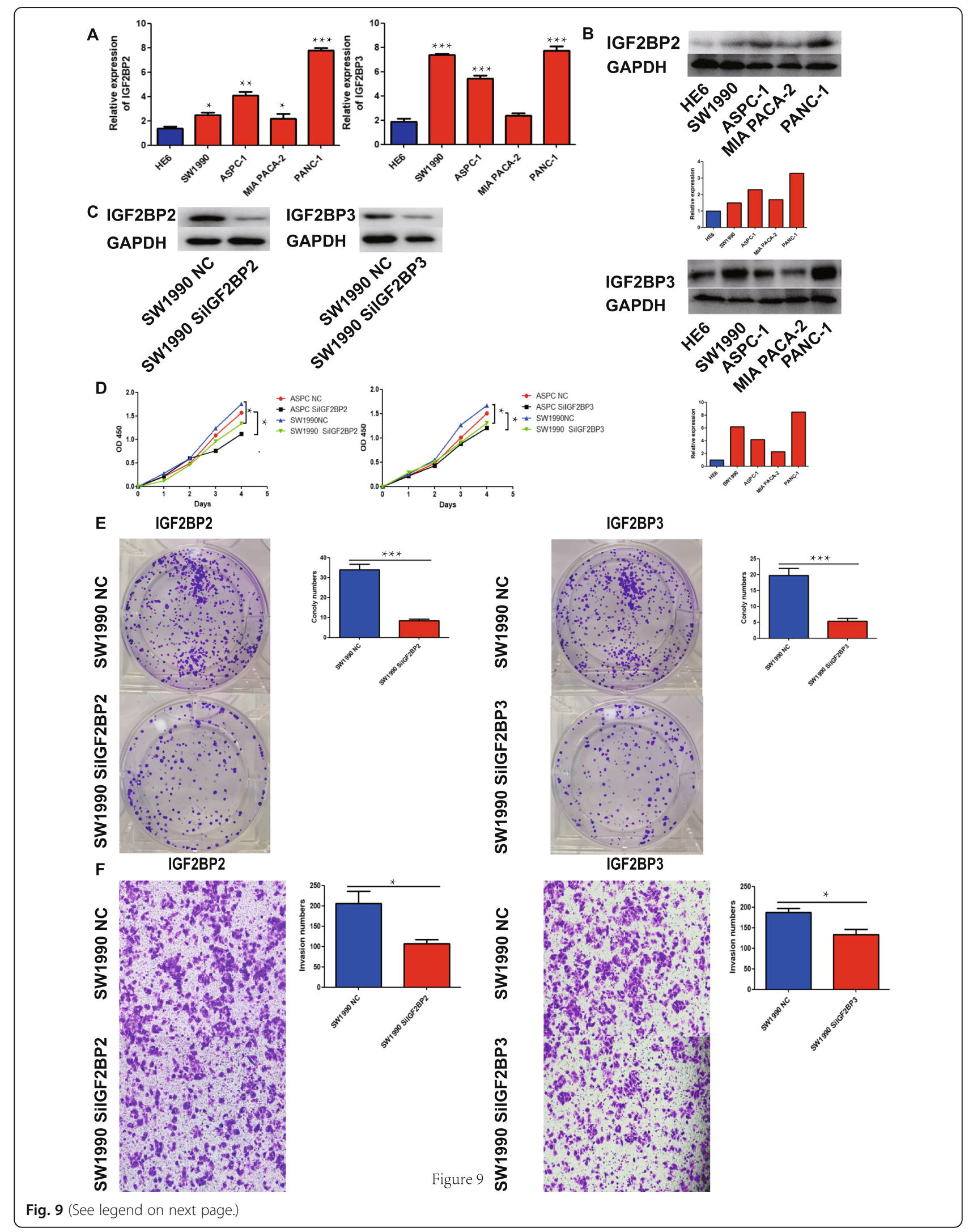


(See figure on previous page.)

Fig. 9 a. Expression of IGF2BP2 and IGF2BP3 in pancreatic cancer and normal cell lines. b. Expression of IGF2BP2 and IGF2BP3 in pancreatic cancer and normal cell lines assessed by western blot analysis. c. Proliferation of SW1990 and ASPC-1 cells detected by CCK-8 assays. d. Proliferation of SW1990 (NC vs SilGF2BP2) (NC vs SilGF2BP3) cells detected by colony formation assays. d. Invasion of SW1990 (NC vs SilGF2BP2) (NC vs SilGF2BP3) cells detected by transwell assays (magnification 400x). Data are presented as the mean \pm SD of at least three independent measurements. ${ }^{*} P<0.05,{ }^{*} P<0.01$ and ${ }^{* *} P<0.001 . P<0.05$ was considered statistically significant

In our enrichment analysis, P53 was also upregulated, consistent with the conclusion of Dianov et al. Although the relationship between abnormalities in the BER pathway and the development and prognosis of cancer has been studied [19-21], in pancreatic cancer, whether IGF2BP2 is associated with this process has not yet been elucidated. The positive correlation between pathogenic Escherichia coli (E. coli) infection and colon cancer has been confirmed in multiple studies [22, 23]. The infection of pathogenic $E$. coli destroys the microenvironment of the microflora in the intestinal tract, thereby inducing colon cancer [22-24]. In studies of pathogenic Escherichia coli infection-induced pathways for pancreatic cancer, there is a lack of clear evidence that this pathway is associated with pancreatic cancer. The upregulation of IGF2BP3 expression in pancreatic cancer tissues supports research on this pathway. IGF2BP3 imbalanceinduced pancreatic cancer may be related to pathogenic E. coli infection.

The autoimmune response to IGF2BP2 observed in hepatocellular carcinoma and colorectal, ovarian, and breast cancers supports the potential of autoantibodies against IGF2BP2 as biomarkers for cancer screening, diagnosis, and prognosis [5]. Consistent with the results of our Cox regression model in pancreatic cancer, the overexpression of IGF2BP2 in basal-like breast cancer and oesophageal adenocarcinoma predicts short-term survival for patients. At the cellular level, IGF2BP2 enhances genome instability and stimulates cancer cell proliferation and migration. Cao et al. believed that the dysregulation of IGF2BP2 was related to insulin resistance, diabetes and carcinogenesis and may potentially become a powerful biomarker and candidate target for related diseases [24]. In fact, IGF2BP3 might differentiate normal tissues from cancerous tissues and serve as a prognostic marker for colorectal, hepatocellular, and ovarian clear-cell carcinomas [25-27]. Previous research has confirmed that IGF2BP3 is involved in cell growth and migration in early embryonic development [28]. Similarly, both of our results confirmed the role of IGF2BP2 and IGF2BP3 in inhibiting tumour progression.

\section{Conclusion}

In summary, we successfully revealed that members of the IGF2BP protein family can be used for the diagnosis and prognosis of advanced pancreatic cancer. Both
IGF2BP2 and IGF2BP3 have great potential to become biomarkers for pancreatic cancer, as verified in patients. Although we explored the mutation types and possible carcinogenic mechanisms of IGF2BP2 and IGF2BP3 in pancreatic cancer, the mechanisms that promote the progression of pancreatic cancer need further study.

\section{Supplementary Information}

The online version contains supplementary material available at https://doi. org/10.1186/s12885-020-07590-x.

Additional file 1 : Supplemental Figure 1. Top 10 pathways revealed by GO and KEGG enrichment analyses of IGF2BP2 and IGF2BP3 (differentially expressed genes); GO, Gene Ontology; KEGG, Kyoto Encyclopedia of Genes and Genomes. Table S1. Primers and SiRNA sequences used in this research $\left(5^{\prime}-3^{\prime}\right)$.

\section{Abbreviations}

IGF2BP: The insulin-like growth factor 2 mRNA binding protei; TCGA: The Cancer Genome Atlas; GEPIA: Gene Expression Profiling Interactive Analysis; OS: Overall Survival; GSEA: Gene Set Enrichment Analysis; IMP: IGF-II mRNA binding proteins; KH: hnRNPK homology; GTEx: Genotype-Tissue Expression; KEGG: Kyoto Encyclopedia of Genes and Genomes; GO: Gene Ontology; DAVI D: The Database for Annotation, Visualization, and Integrated Discovery; CDNA: Complementary DNA; CCK-8: The Cell Counting Kit-8; OD: Optical Density; PMSF: Phenylmethanesulfonyl Fluoride; DTT: DL-dithiothreitol; E. coli: Escherichia coli

\section{Acknowledgements \\ None.}

\section{Authors' contributions}

$\mathrm{XHC}$ and $\mathrm{XHQ}$ designed the study. CFZ collected the data. XHC and SYH performed the data analyses and produced the initial draft of the manuscript. XHC obtained and validated the results. All authors read and approved the final manuscript.

\section{Funding}

This study was supported by the Social Development Foundation of Science and Technology of Jiangsu (BE2016658), and the Project of Changzhou medical innovation team (CCX201807). The funder had no influence in the design of the study, the collection, analysis and interpretation of data, and in the writing of the manuscript.

\section{Availability of data and materials}

The datasets used and analysed during the current study are available from the corresponding author on reasonable request.

\section{Ethics approval and consent to participate}

This study was approved by the Academic Committee of Changzhou Second People's Hospital affiliated with Nanjing Medical University and was conducted in accordance with the principles expressed in the Helsinki Declaration. All datasets were obtained from published literature, so it can be confirmed that written informed consent was obtained.

Consent for publication

Not applicable. 


\section{Competing interests}

The authors declare no competing interests.

\section{Author details}

'Department of General Surgery, the Affiliated Changzhou No. 2 People's Hospital of Nanjing Medical University, 68 Pohu Middle Road, Changzhou, Jiangsu 213000, P.R. China. ${ }^{2}$ Nanjing Medical University, Nanjing, Jiangsu 211166, P.R. China. ${ }^{3}$ Department of General Surgery, Liver Transplantation Center, The First Affiliated Hospital of Nanjing Medical University, Nanjing, Jiangsu, P.R. China.

Received: 12 August 2020 Accepted: 29 October 2020

Published online: 27 November 2020

\section{References}

1. Siegel RL, Miller KD, Jemal A. Cancer statistics, 2019. CA Cancer J Clin. 2019; 69(1):7-34.

2. Moore A, Donahue T. Pancreatic Cancer. JAMA. 2019;322(14):1426

3. Chen W, Zheng $R$, Baade PD, Zhang S, Zeng H, Bray F, Jemal A, Yu XQ, He J. Cancer statistics in China, 2015. CA Cancer J Clin. 2016;66(2):115-32.

4. Allemani C, Matsuda T, Di Carlo V, Harewood R, Matz M, Niksic M, Bonaventure A, Valkov M, Johnson CJ, Esteve J, et al. Global surveillance of trends in cancer survival 2000-14 (CONCORD-3): analysis of individual records for 37513025 patients diagnosed with one of 18 cancers from 322 population-based registries in 71 countries. Lancet. 2018;391(10125):102375.

5. Bell JL, Wachter K, Muhleck B, Pazaitis N, Kohn M, Lederer M, Huttelmaier S. Insulin-like growth factor 2 mRNA-binding proteins (IGF2BPs): posttranscriptional drivers of cancer progression? Cell Mol Life Sci. 2013;70(15): 2657-75.

6. Liao B, Hu Y, Brewer G. RNA-binding protein insulin-like growth factor mRNA-binding protein 3 (IMP-3) promotes cell survival via insulin-like growth factor II signaling after ionizing radiation. J Biol Chem. 2011;286(36): 31145-52.

7. Nielsen J, Christiansen J, Lykke-Andersen J, Johnsen AH, Wewer UM, Nielsen FC. A family of insulin-like growth factor II mRNA-binding proteins represses translation in late development. Mol Cell Biol. 1999;19(2):1262-70.

8. Huang $H$, Weng $H$, Sun W, Qin X, Shi H, Wu H, Zhao BS, Mesquita A, Liu C, Yuan $\mathrm{CL}$, et al. Recognition of RNA N (6)-methyladenosine by IGF2BP proteins enhances mRNA stability and translation. Nat Cell Biol. 2018;20(3): 285-95.

9. Wachter K, Kohn M, Stohr N, Huttelmaier S. Subcellular localization and RNP formation of IGF2BPs (IGF2 mRNA-binding proteins) is modulated by distinct RNA-binding domains. Biol Chem. 2013;394(8):1077-90.

10. Farina KL, Huttelmaier S, Musunuru K, Darnell R, Singer RH. Two ZBP1 KH domains facilitate beta-actin mRNA localization, granule formation, and cytoskeletal attachment. J Cell Biol. 2003;160(1):77-87.

11. Nielsen J, Kristensen MA, Willemoes M, Nielsen FC, Christiansen J. Sequential dimerization of human zipcode-binding protein IMP1 on RNA: a cooperative mechanism providing RNP stability. Nucleic Acids Res. 2004 32(14):4368-76.

12. Grutzmann R, Pilarsky C, Ammerpohl O, Luttges J, Bohme A, Sipos B, Foerder M, Alldinger I, Jahnke B, Schackert HK, et al. Gene expression profiling of microdissected pancreatic ductal carcinomas using high-density DNA microarrays. Neoplasia. 2004;6(5):611-22.

13. Pei H, Li L, Fridley BL, Jenkins GD, Kalari KR, Lingle W, Petersen G, Lou Z, Wang L. FKBP51 affects cancer cell response to chemotherapy by negatively regulating Akt. Cancer Cell. 2009;16(3):259-66.

14. Badea L, Herlea V, Dima SO, Dumitrascu T, Popescu I. Combined gene expression analysis of whole-tissue and microdissected pancreatic ductal adenocarcinoma identifies genes specifically overexpressed in tumor epithelia. Hepatogastroenterology. 2008;55(88):2016-27.

15. Ishikawa M, Yoshida K, Yamashita Y, Ota J, Takada S, Kisanuki H, Koinuma K, Choi YL, Kaneda R, Iwao T, et al. Experimental trial for diagnosis of pancreatic ductal carcinoma based on gene expression profiles of pancreatic ductal cells. Cancer Sci. 2005;96(7):387-93.

16. Segara D, Biankin AV, Kench JG, Langusch CC, Dawson AC, Skalicky DA Gotley DC, Coleman MJ, Sutherland RL, Henshall SM. Expression of HOXB2, a retinoic acid signaling target in pancreatic cancer and pancreatic intraepithelial neoplasia. Clin Cancer Res. 2005;11(9):3587-96.
17. Caffrey PJ, Delaney S. Chromatin and other obstacles to base excision repair: potential roles in carcinogenesis. Mutagenesis. 2020;35(1):39-50.

18. Poletto M, Legrand AJ, Fletcher SC, Dianov GL. p53 coordinates base excision repair to prevent genomic instability. Nucleic Acids Res. 2016;44(7): 3165-75.

19. Ray D, Kidane D. Gut microbiota imbalance and base excision repair dynamics in Colon Cancer. J Cancer. 2016;7(11):1421-30.

20. Vodenkova S, Jiraskova K, Urbanova M, Kroupa M, Slyskova J, Schneiderova M, Levy M, Buchler T, Liska V, Vodickova L, et al. Base excision repair capacity as a determinant of prognosis and therapy response in colon cancer patients. DNA Repair (Amst). 2018:72:77-85.

21. Vodicka P, Urbanova M, Makovicky P, Tomasova K, Kroupa M, Stetina R, Opattova A, Kostovcikova K, Siskova A, Schneiderova M, et al. Oxidative damage in sporadic colorectal cancer: molecular mapping of base excision repair glycosylases in colorectal cancer patients. Int J Mol Sci. 2020;21(7): 2473.

22. Khan S, Zaidi S, Alouffi AS, Hassan I, Imran A, Khan RA. Computational proteome-wide study for the prediction of Escherichia coli protein targeting in host cell organelles and their implication in development of Colon Cancer. ACS Omega. 2020;5(13):7254-61.

23. Khan S. Potential role of Escherichia coli DNA mismatch repair proteins in colon cancer. Crit Rev Oncol Hematol. 2015:96(3):475-82.

24. Cao J, Mu Q, Huang $\mathrm{H}$. The roles of insulin-like growth factor 2 mRNAbinding protein 2 in Cancer and Cancer stem cells. Stem Cells Int. 2018; 2018:4217259.

25. Xu W, Sheng Y, Guo Y, Huang Z, Huang Y, Wen D, Liu CY, Cui L, Yang Y, Du P. Increased IGF2BP3 expression promotes the aggressive phenotypes of colorectal cancer cells in vitro and vivo. J Cell Physiol. 2019;234(10):1846679.

26. Gao Y, Luo T, Ouyang X, Zhu C, Zhu J, Qin X. IGF2BP3 and miR191-5p synergistically increase HCC cell invasiveness by altering ZO-1 expression. Oncol Lett. 2020;20(2):1423-31

27. Liu H, Zeng Z, Afsharpad M, Lin C, Wang S, Yang H, Liu S, Kelemen LE, Xu W, Ma W, et al. Overexpression of IGF2BP3 as a potential oncogene in ovarian clear cell carcinoma. Front Oncol. 2019:9:1570.

28. Mancarella C, Scotlandi K. IGF2BP3 from physiology to Cancer: novel discoveries, unsolved issues, and future perspectives. Front Cell Dev Biol. 2019;7:363.

\section{Publisher's Note}

Springer Nature remains neutral with regard to jurisdictional claims in published maps and institutional affiliations.

Ready to submit your research? Choose BMC and benefit from:

- fast, convenient online submission

- thorough peer review by experienced researchers in your field

- rapid publication on acceptance

- support for research data, including large and complex data types

- gold Open Access which fosters wider collaboration and increased citations

- maximum visibility for your research: over $100 \mathrm{M}$ website views per year

At BMC, research is always in progress.

Learn more biomedcentral.com/submission 